\title{
Developing User Persona Based on the Factors of Visitor Recreation Activities in Hongneung Experimental Forest
}

\author{
Youn-Sun Jang, Rhee-Hwa Yoo*, and Jeong-Hee Lee \\ Forest Welfare Division, National Institute of Forest Science, Seoul, 02455, Korea
}

\section{ABSTRACT}

Much research has been conducted on user behavior by taking surveys and interviews to plan the green space effectively. However, there is a limitation in understanding detailed user characteristics such as personalities and values. This study applied the Persona-based Scenario Method (PSM) to Hongneung Experimental Forest to understand the detailed needs and behaviors of the users in the forest recreation area. The PSM is a user experience modeling technique, which tries to understand the users by describing the type of users as real people. This study 1) extracts the factors of visitor recreation activities in Hongneung Experimental Forest based on the results of the survey, 2) develops user personas based on the results of survey and comes up with activity factors, and 3) designs user scenarios. As a result of applying the PSM, 64 factors of visitor activities were derived from the observation survey in 14 sites of Hongneung Experimental Forest and 25 key factors of visitor activities were chosen through observer's brainstorming. Second, three types of personas were developed considering the key factors and the results of user characteristics with quantitative and qualitative analysis. Lastly, context scenarios were designed by applying the key factors of visitor recreation activities to the persona model. We identified the design problems of the space and design requirements through the scenarios. This study has significance in that it takes an approach from the user perspective and was applied to the forest recreation area, which was mainly used in product design. The developed personas could be used for deriving design elements and setting the direction for planning considering detailed needs, behaviors and characteristics of users.

Keywords: characteristics, design, forest, PSM(persona-based scenario method), user behavior

\section{Introduction}

As more and more people visit forests for recreation, various forest recreation areas such as recreational forests, healing forests, forest experience centers for little children, forest parks and urban forests are growing quantitatively. With this trend, discussions have been made in various perspectives to improve the quality of forest recreation services, such as location of the forest recreation area (T.H. Kim, 2016), space planning (Lee et al., 2015), programs and contents (T.W. Kim, 2016; Y.H. Kim, 2016). The physical environment of space where users have various experiences is especially an important element that has a relatively great effect on user satisfaction.

Meanwhile, 'user-centered planning' is a highly important goal in space design. To create a space in the perspective of not the designer but the user, various discussions have been made on 'user-centered design (UCD),' 'human-centered space design(J.M. Lee, 2013),' and 'interaction design' (Kang and Kwon, 2005; J.H. Lee, 2013). To achieve this goal, there have been many attempts in forest recreation to determine user characteristics by examining user behavior in forests or green spaces (Jang and Son, 2017; Son and Ha, 2012), awareness (Chang, 2001), user satisfaction (Chang and Bae, 2001; Ryu, 2017), and preference (Chang, 2001; Cho and Im, 2013). However, previous

Received: August 28, 2019, Revised: September 16, 2019, Accepted: October 2, 2019

First author: Youn-Sun Jang, sofia410@korea.kr, (D) https://orcid.org/0000-0002-0298-5662

*Corresponding author: Rhee-Hwa Yoo, cham0505@korea.kr, (1) https://orcid.org/0000-0002-7746-7712 
studies were mostly surveys on users. A survey is a research tool that is most generally used to efficiently determine user opinions in short time (Zaller, 1992), but its disadvantage is that it is conducted in a short period of time and thus cannot bring out the true intentions or in-depth attitudes of respondents (Kang et al., 2007), and may also miss certain things statistically (Lee et al., 2007). Thus far, studies on forest recreation have been focused on superficial examinations such as age, gender, duration of stay and purpose of use, thereby limited in determining detailed characteristics such as user values or experiences.

To overcome these limitations, this study applied the persona-based scenario method (PSM) that can thoroughly determine even the parts that are not revealed in detail to the case of Hongneung Experimental Forest, by subdividing user characteristics based on their values and personalities and analyzing them in multiple aspects. The PSM is a technique that models the experiences of users with representativeness and is used as a tool to understand users with certain purposes by describing them as characters that actually exist (Kim and An, 2018). Persona is especially characterized by the fact that it covers abundant stories about user attitudes, purposes and behaviors and is made with qualitative data obtained from 1:1 interviews and observations (Kwon et al., 2017). This study comes up with factors of visitor activities in the study area based on the results of field investigation and sets up personas based on the user characteristics, thereby presenting an archetype of the scenario.

\section{Research Methods}

\section{Theoretical considerations}

\section{Concept and components of persona}

The PSM is a tool to understand users in user experience design and a methodology that describes users with specific purposes as characters that actually exist (An and Kim, 2015). Software designer Alan Cooper's book 'The Inmates are Running the Asylum(Cooper, 2004)' first introduced the components, characteristics and development methods of persona, which were specified into a user-centered de- sign method through his book 'About Face(Cooper et al., 2007)' in 1995 (Song, 2009). Persona is a user design model that is not a real person; it is a virtual character created based on a group of multiple users observed in research. Personas are given their personalities and individualities based on all kinds of data obtained from user interviews and observations and are classified by the similarities they share in terms of experience (Jeong and Jung, 2014).

Personas are made by determining major behavior patterns and converting them into useful characters (Kwon et al., 2017). Creating elaborate personas requires components such as personal background, relationship with the design subject, purpose of use/need/attitude, specific knowledge/skill, and context of use (Olsen, 2004; Song, 2009). Thus, it is necessary to design a field study considering the components of personas.

\section{Use of the PSM and research trend}

The PSM first began to be used in product or software development and is now a very commonly used method (Song, 2009). Other countries mostly use the PSM to determine customer needs in product design, and Korea is attempting to apply the PSM in various fields from software, product development and design to humanities and philosophy, fashion marketing, urban design, architecture, and transportation.

Positive aspects of the PSM in product development have been discussed many times (Anvari et al., 2017; Miaskiewicz and Kozar, 2011), and the PSM has also been used to improve automotive navigation (Oh et al., 2010) or SNS mobile application functions (Chung, 2013). The PSM especially can be used as a measure to easily assess the reflection status in planning or design (Song, 2009). Thus, recently it is used to reflect user behaviors and experience factors to plan U-zone and U-city experience zone as a 'human'-centered space (An and Kim, 2015; Lee et al., 2007). There is also a case in which it is used to systematically analyze user behavior and needs for planning/design of public space (Song, 2009). The PSM is also applied to make a walking map in Smart City from the user perspective (Ahn et al., 2014), which implies that it is actively used in urban design, architecture, transportation, and regional 


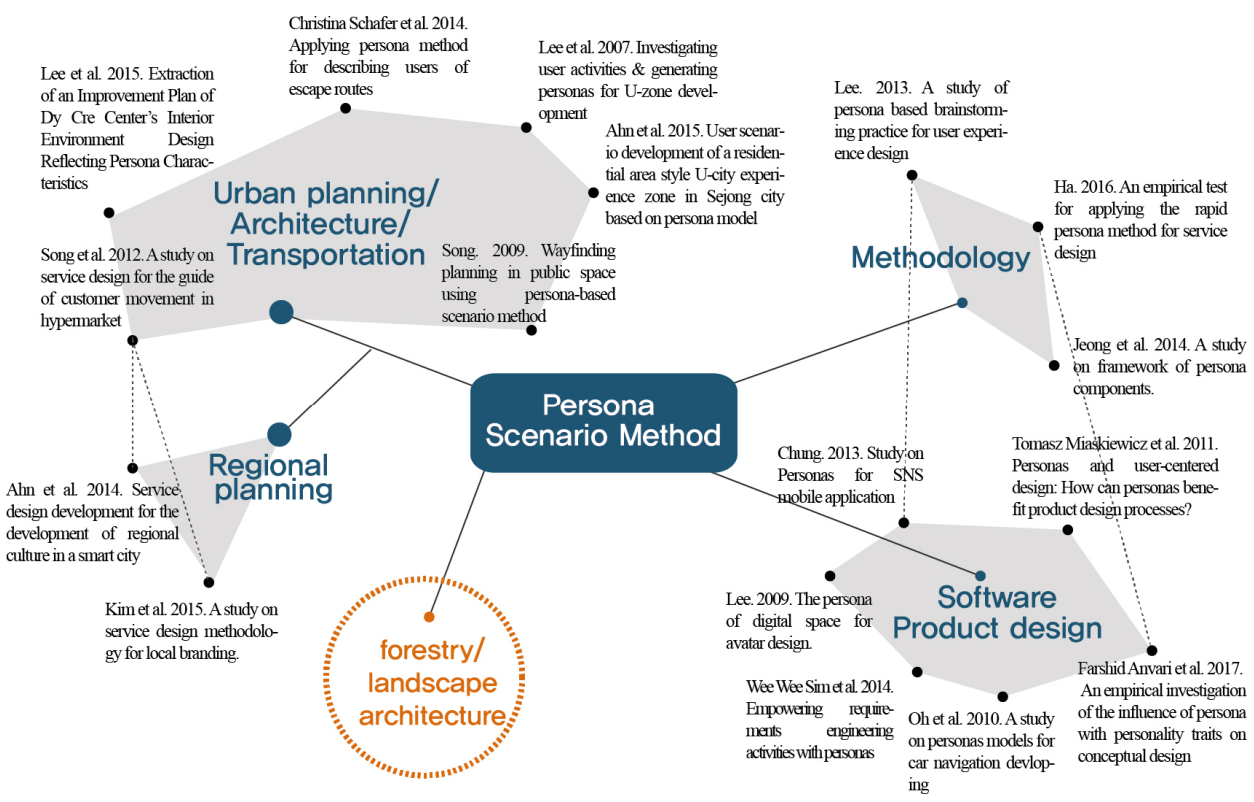

Fig. 1. Current studies on Personal Scenario Method.

planning. It makes user-centered design possible as it takes an approach from the user perspective from the initial stage by setting a persona that represents various user bases (Song, 2009). However, there is no case thus far in which the PSM is applied to the natural environment such as forests or parks aside from urban areas (Fig. 1).

\section{Scenario-based design process}

The derived personas form events with narrative stories according to scenarios. A scenario refers to a story composed along the path when the persona has a series of use cases with the design subject with a clear purpose, and it requires three elements: environmental setting, actor, and action/event (Song, 2009; Wiegers, 2003). Generally in planning or design, the current states or requirements are derived to establish planning/design concepts through the context scenario, and interactions between the persona and the design subject are described in detail through the key path scenario. Finally, the validation scenario, which substitutes the plan about the problems, requirements and ideal situations in the context scenario, is used to verify the design solutions (Song, 2009). This study is conducted with focus on designing a context scenario to determine user needs and characteristics, and the parts with focus are marked in gray in the figure below (Fig. 2).

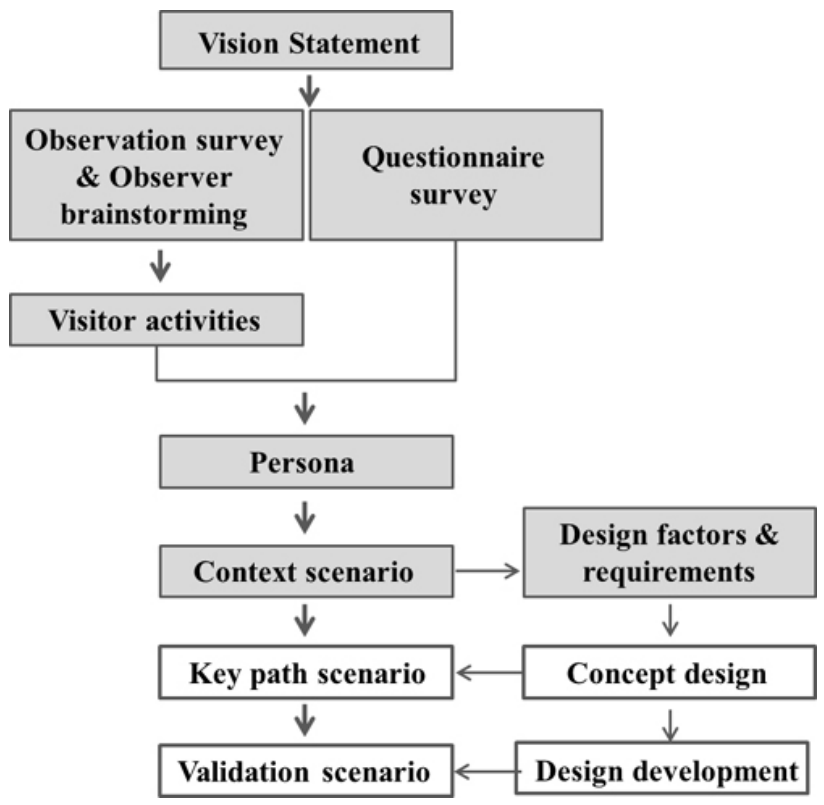

Fig. 2. Flowchart of PSM(persona-based scenario method) design process.

Since a scenario provides a detailed description of interactions that occur in each step, it can systematically summarize the entire design process, while also reflecting the real situations of users by describing user experience (Lee et al., 2007). Moreover, it facilitates the development of concepts and ideas by understanding the problems from the user perspective and can obtain secondary data that 


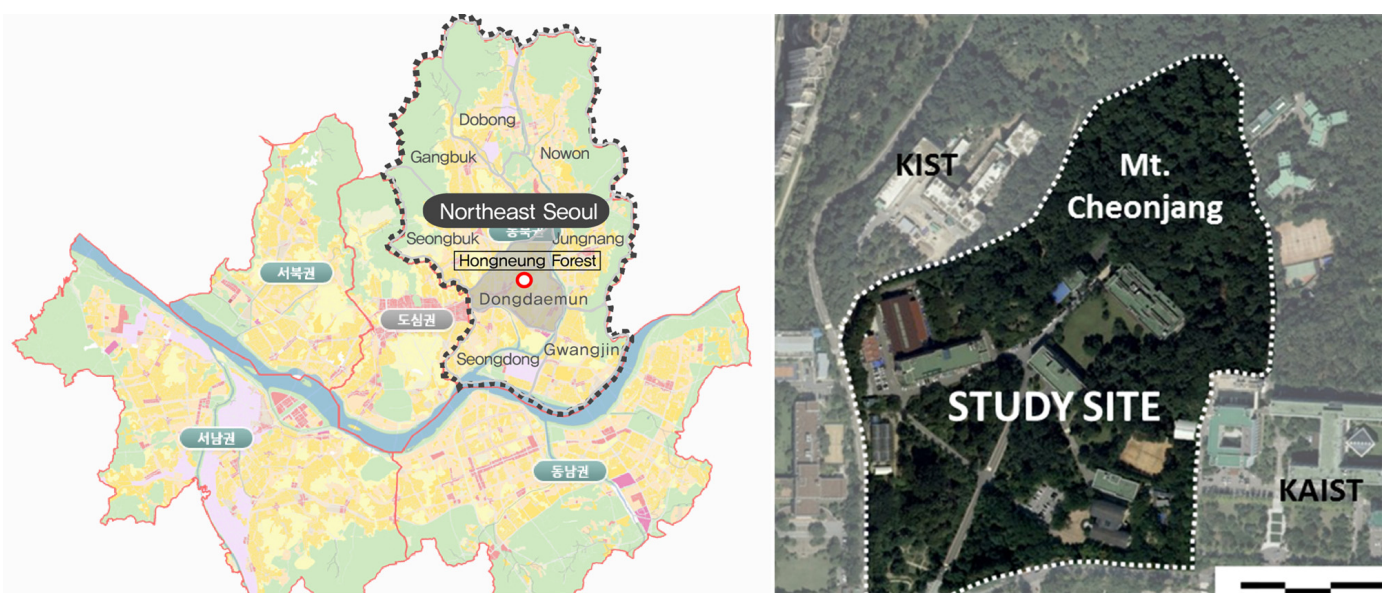

Fig. 3. Location of Hongneung Experimental Forest at Dongdaemun-gu, Seoul.

is generally difficult to acquire, which is why it is recently used actively in both public and private sectors (An and Kim, 2015).

\section{Methods}

The study area is Hongneung Experimental Forest in the Korea Forest Research Institute in Dongdaemun-gu, northeast Seoul, located at the southwestern foot of Cheonjangsan Mountain (141m) in the east of Seoul. There are gardens in 12 themes in the area of 440 thousand $\mathrm{m}^{2}$ including needleleaf tree garden, broad-leaved tree garden, warm temperate arboretum, and medicinal plant garden, as well as six scenic trails (Trail of Munbae Tree, Trail of Millennium Forest, Empress's Trail, Trail of Cheonjang-maru, Trail of Forest Adventure). Moreover, it is open on weekends for nature learning and environmental education, and currently about 210 thousand people are visiting it every year (Choi and Kim, 2015). Since it has only one entrance and its scenic trails are not complicated, we decided that the forest is suitable for observation survey. In addition, it is open only on weekends so that it is easy to observe various recreational actions of users at the same time, which is why we selected Hongneung Experimental Forest as the study site (Fig. 3).

Meanwhile, the key to the PSM is to adequately use methods such as field observation surveys, interviews and examinations of circumstances (Lee and Nam, 2015). Therefore, we used user data uploaded on hiking applica-

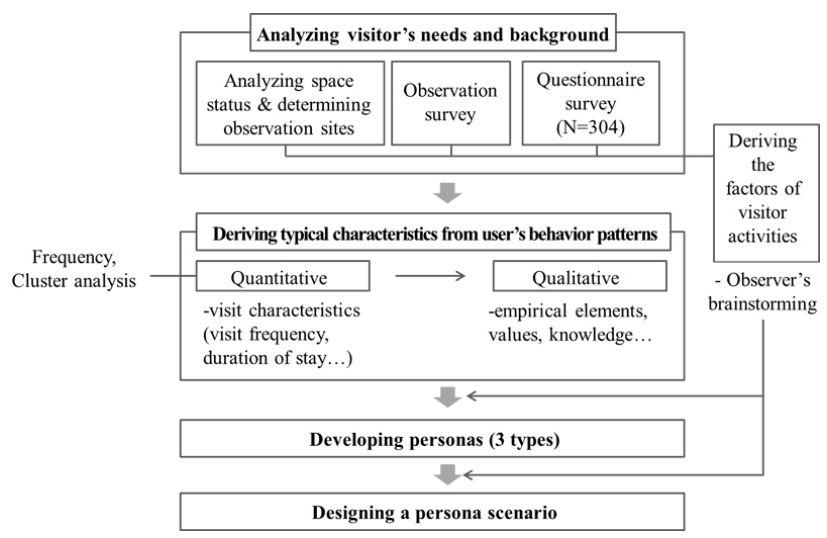

Fig. 4. Research process flowchart.

tions to analyze the physical status of Hongneung Experimental Forest and select observation spots. Moreover, observation and questionnaire surveys were conducted to determine user needs within the space. Then we quantitatively and qualitatively analyzed the results of the observation and questionnaire surveys, after which we designed a persona scenario based on the factors of visitor activities derived through four observation surveys and observer's brainstorming. For quantitative analysis, we conducted frequency analysis and cluster analysis (Fig. 4).

The questionnaire survey was conducted at the main entrance of Hongneung Experimental Forest on 304 weekend visitors aged 19 and older on June 2-3, 2018 and September $1-2,2018$. We analyzed 299 out of 304 copies of the questionnaire, excluding five copies with omitted or inconsistent responses. Detailed survey items were in six categories (personal background, relationship with the design sub- 
ject/purpose/need/attitude, overall behavior, inconvenience/ satisfaction, experience, specific knowledge/skill) with reference to the components for persona development (Olsen, 2004; Table 1). Detailed items included personal characteristics such as occupation and age, usage patterns such as use visit frequency and companion, purpose of visit, values about nature, activities before/during/after experience, problems and points to improve within the area, satisfaction, activities, visiting spot and circulation, knowledge and skills about the forest, etc. For values about nature, we used a 5 -point scale ( 1 point=strongly disagree; 5 points=strongly agree) for six Experience Items from the Korean version of the Nature Relatedness Scale (NRS; J.H. Lee, 2013). Greater sum of each item indicates higher nature relatedness. For knowledge about nature, we had the visitors write down the number of insects, birds, wildflowers and tree species they know.

For analysis, we conducted a frequency analysis to determine the basic characteristics of respondents, such as gender, age, residential area, occupation, purpose of visit, means of transportation, number of companions, companion type, visit experience, visit motivation and visit frequency. Moreover, to categorize the types of persona, we conducted two-stage cluster analysis that can use categorical variables and continuous variables in the analysis and used cross-tabulation analysis to determine the attributes of each cluster. After that, we conducted a qualitative analysis to specify each persona.

\section{Results and Discussion}

\section{Deriving factors of visitor activities through observation survey}

Since observation is an essential process for extensively reflecting the position of the subjects away from the designer's limited perspective in persona scenario development (Song, 2009), this study also conducted an observation survey in key spots. Prior to the observation survey, we used two commercial hiking applications to superimpose the circulation of users through QGIS Heatmap analysis and came up with spaces that were frequently visited by users in Hongneung Experimental Forest (former site of Hongneung, Scenic Tree Species Garden, Millennium Hill, etc.). Focusing on these spots, we selected 14 observation spots (coniferous garden, deck walkway, picnic table, cherry rest area, wooden stairs, stand, Forest Science Exhibition Hall, information board, Millennium Hill, former site of Hongneung, Scenic Tree Species Garden, tree stump rest area, swing rest area, medicinal garden/wetlands) that are easy to observe and determined user activities and circulation patterns of weekend users (Fig. 5).

As a result of the observation survey, we came up with 64 factors of visitor activities (excluding redundant items) by area. Actions or behaviors refer to physical and mental activities with certain purpose or desire, and thus we specifically listed them considering that they are goal-oriented and consciously conducted (Song, 2006). Then we selected 25 key factors that must be reflected on the scenario making process through observer's brainstorming. The key factors are focused on items that appeared at least twice in

Table 1. Survey items

\begin{tabular}{ll}
\hline \multicolumn{1}{c}{ Component } & \multicolumn{1}{c}{ Item } \\
\hline Personal background & $\bullet$ (Demograhic variables) age, gender, occupation, residential area, \\
& personality, participating group, hobbies, etc. \\
& - (Visit pattern) visit motivation, visit experience, purpose, frequency, \\
& companion type, the number of companion, transportation
\end{tabular}




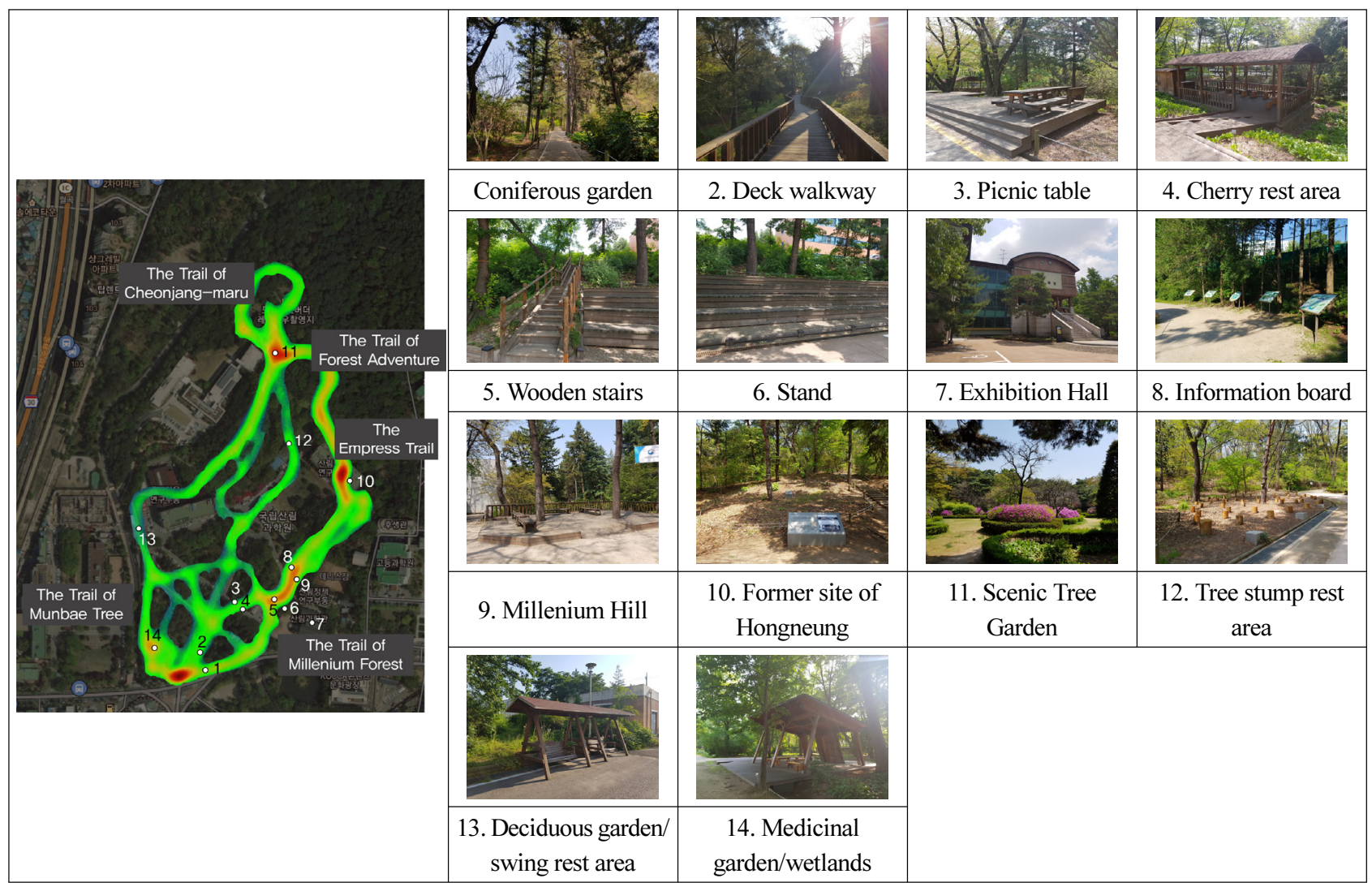

Fig. 5. Selected 14 observation points in Hongneung Experimental Forest to observe user patterns.

the field study result of observers. The derived factors of visitor activities were then sorted by integrating similar items and excluding meaningless ones (Table 2).

\section{Analyzing user characteristics through the questionnaire survey and interview}

We conducted the questionnaire survey and interview to obtain basic data to come up with types of persona by deriving actual user characteristics and needs. The results showed that there were more male respondents $(57.9 \%)$ than female, and many of them were over 60 s $(34.2 \%)$ or in their 50s (21.7\%). Most of them were employees/public officials $(22.7 \%)$, followed by homemakers $(21.7 \%)$. The percentage of respondents visiting from Seoul $(41.1 \%)$ was similar to that visiting from Dongdaemun-gu (37.5\%), indicating that Hongneung Experimental Forest is used as a neighborhood forest by local residents. As for user characteristics, there were more respondents with previous visit experience $(72.9 \%)$ than those without experience $(27.1 \%)$.
The respondents mostly visited on a weekly basis (14.0\%) for physical health $(21.7 \%)$ and to appreciate nature (20.4\%), usually in pairs (43.5\%) and accompanied by family and relatives (47.2\%) on foot (54.2\%). Many of them already knew about Hongneung Experimental Forest and visited since it is close to their residence (44.1\%) or were introduced by acquaintances (35.8\%; Table 3).

We conducted the Korean version of the Nature Relatedness Scale (NRS) to determine values about nature (J.H. Lee, 2013) and found that the mean of respondents was 3.59 on a 5-point scale, and the highest score was 3.99 in 'Item No. 5 (I often go out in nature)'. For knowledge about nature, we had the respondents write down the number of insects, birds, wildflowers and tree species that they know and found that they knew relatively more wildflowers (19.97 species) and trees (16.50 species) than insects (9.48 species) and birds (7.28 species; Table 4).

We conducted cluster analysis on variables that can be quantitatively analyzed based on the basic survey data and subdivided the derived types by conducting a qualitative 
Table 2. Factors of visitor activities and key factors

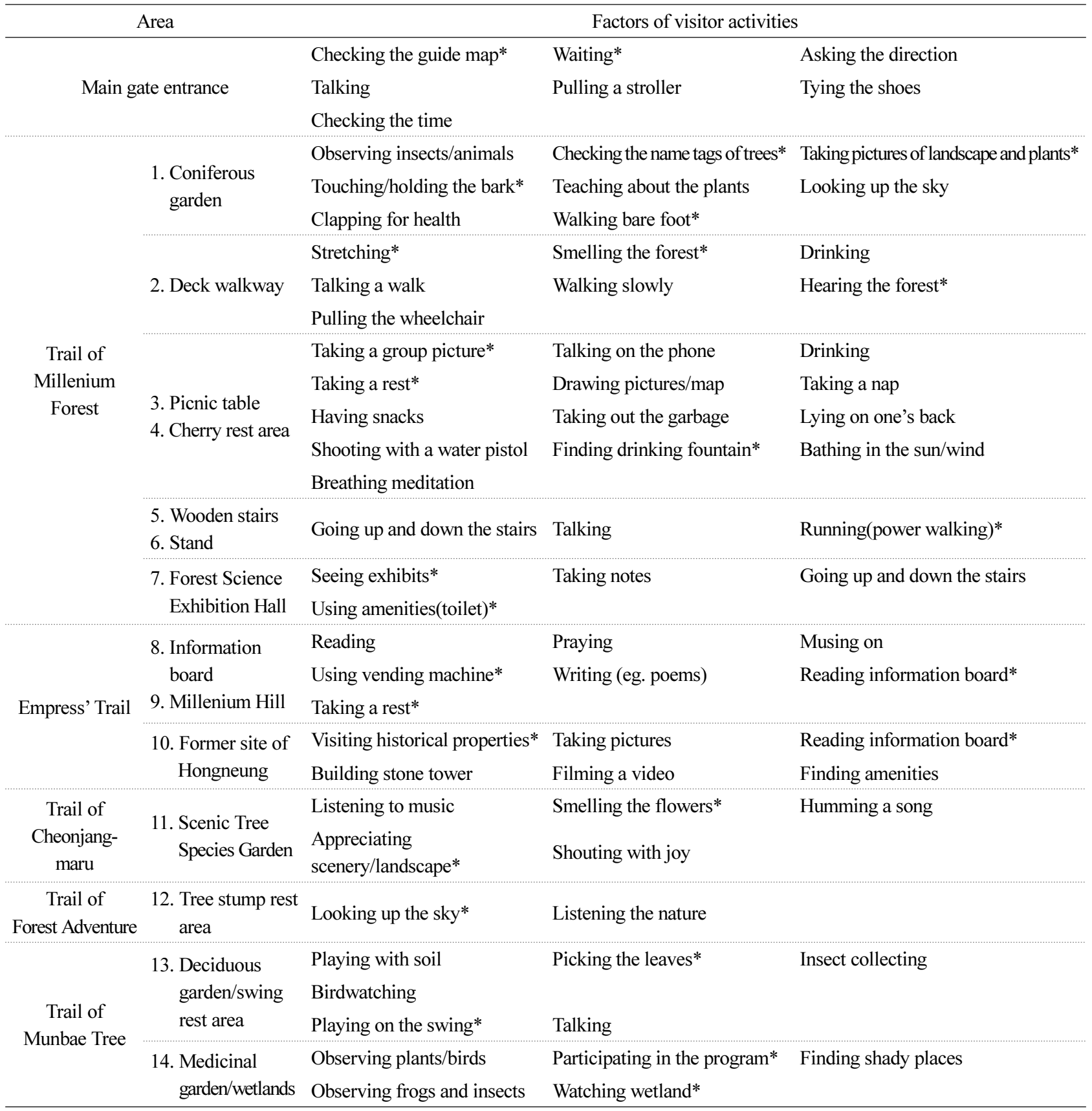

Note. Key factors of visitor activities are marked with an asterisk.

analysis. In this study, we used the 2-stage cluster analysis that can use categorical variables and continuous variables in the analysis. We set the maximum range of cluster analysis as 15 and had the number of clusters be decided automatically within the range based on the Schwarz-Bayesian criterion (BIC). As a result of analysis considering BIC changes and ratio of distance measures, three clusters were showing optimum cluster values (Table 5). Accordingly, cross-tabulation analysis was conducted to determine the characteristics of each cluster. After that, we conducted a qualitative analysis by cluster on items such as hobbies, group activities, activities before and after the visit, points to improve, places of visit, knowledge about forests, and values about nature, thereby examining each cluster's char- 
Table 3. Demographic and visit characteristics of visitors ( $N=299)$

\begin{tabular}{|c|c|c|c|c|c|c|c|}
\hline & Variable & $\mathrm{n}$ & $\%$ & & Variable & $\mathrm{n}$ & $\%$ \\
\hline \multirow{2}{*}{ Gender } & Male & 126 & 42.1 & \multirow{7}{*}{$\begin{array}{l}\text { Purpose of } \\
\text { visit }\end{array}$} & Appreciating nature & 61 & 20.4 \\
\hline & Female & 173 & 57.9 & & Relieving stress & 34 & 11.4 \\
\hline \multirow{5}{*}{ Age } & $20 \mathrm{~s}$ & 39 & 13.0 & & Spending leisure time & 45 & 15.1 \\
\hline & $30 \mathrm{~s}$ & 38 & 12.7 & & Social interaction & 52 & 17.4 \\
\hline & $40 \mathrm{~s}$ & 55 & 18.4 & & Health & 65 & 21.7 \\
\hline & $50 \mathrm{~s}$ & 65 & 21.7 & & Education & 16 & 5.4 \\
\hline & over $60 \mathrm{~s}$ & 102 & 34.2 & & Others & 26 & 8.6 \\
\hline \multirow{4}{*}{$\begin{array}{l}\text { Residential } \\
\text { area }\end{array}$} & Dongdaemun-gu, Seoul & 112 & 37.5 & \multirow{5}{*}{$\begin{array}{l}\text { Means of } \\
\text { transportation }\end{array}$} & On foot & 162 & 54.2 \\
\hline & Seoul except Dongdaemun-gu & 123 & 41.1 & & Bicycle & 4 & 1.3 \\
\hline & Gyunggi/ Incheon & 37 & 12.4 & & Car & 42 & 14.0 \\
\hline & Others & 27 & 9.0 & & Bus, taxi, or subway & 88 & 29.4 \\
\hline \multirow{6}{*}{ Occupation } & Employee/public official & 68 & 22.7 & & Others & 3 & 1.0 \\
\hline & Professional & 51 & 17.1 & \multirow{5}{*}{$\begin{array}{l}\text { Companion } \\
\text { type }\end{array}$} & Family and relatives & 141 & 47.2 \\
\hline & Self-employed/business & 28 & 9.4 & & Friends or couple & 50 & 16.7 \\
\hline & Student & 25 & 8.4 & & Alone & 56 & 18.7 \\
\hline & Homemaker & 65 & 21.7 & & Organization(club, community) & 43 & 14.4 \\
\hline & Unemployed/others & 56 & 18.7 & & Others & 9 & 3.0 \\
\hline \multirow{2}{*}{$\begin{array}{c}\text { Visit } \\
\text { experience }\end{array}$} & Visited & 218 & 72.9 & \multirow{4}{*}{$\begin{array}{l}\text { Number of } \\
\text { companion }\end{array}$} & 1(alone) & 56 & 18.7 \\
\hline & Never visited & 81 & 27.1 & & 2 people & 130 & 43.5 \\
\hline \multirow{6}{*}{$\begin{array}{c}\text { Visit } \\
\text { frequency }\end{array}$} & None & 81 & 27.1 & & 3 people & 33 & 11.0 \\
\hline & A weekly basis & 42 & 14.0 & & More than 4 people & 80 & 26.8 \\
\hline & A monthly basis & 76 & 21.4 & \multirow{4}{*}{$\begin{array}{c}\text { Visit } \\
\text { motivation }\end{array}$} & Online/SNS & 45 & 15.1 \\
\hline & A yearly basis & 54 & 18.1 & & Newspaper/magazine & 12 & 4.0 \\
\hline & Less than a yearly basis & 46 & 15.4 & & Recommendation from others & 107 & 35.8 \\
\hline & & & & & Proximity of the residence & 132 & 44.1 \\
\hline
\end{tabular}

Table 4. Survey results of NRS and knowledge about the forest ecosystem

\begin{tabular}{|c|c|c|c|}
\hline Factor & Questionnaire & M & Total \\
\hline \multirow{6}{*}{$\begin{array}{l}\text { Nature } \\
\text { Relatedness } \\
\text { Scale } \\
\text { (NRS) }\end{array}$} & 1. I enjoy being outdoors, even in unpleasant weather. & 3.49 & \multirow{6}{*}{3.59} \\
\hline & 2. My ideal vacation spot would be a remote, wilderness area. & 3.51 & \\
\hline & 3. I enjoy digging in the earth and getting dirt on my hands. & 3.21 & \\
\hline & 4. I take notice of wildlife where I am. & 3.66 & \\
\hline & 5. I often go out in nature. & 3.99 & \\
\hline & 6. The thought of being deep in the woods, away from civilization, is frightening. (Reverse) & 3.69 & \\
\hline \multirow{4}{*}{$\begin{array}{l}\text { Knowledge } \\
\text { about the } \\
\text { forest } \\
\text { ecosystem }\end{array}$} & 1. Write down all insect species that you know and count them & 9.48 & \multirow{4}{*}{13.31} \\
\hline & 2. Write down all bird species that you know and count them & 7.28 & \\
\hline & 3. Write down all wildflower species that you know and count them & 19.97 & \\
\hline & 4. Write down all tree species that you know and count them & 16.50 & \\
\hline
\end{tabular}

Note. 5-point Likert scale was used to measure NRS.

acteristics in detail.

As a result of quantitative and qualitative analysis, three types of personas were derived, each of which has the fol- lowing characteristics. Type 1 is 'exercising in the neighborhood' type with a housewife in her 60 s or older visiting the forest 1-2 times a month on foot for physical health. 
Table 5. Clustering process

\begin{tabular}{ccccc}
\hline Number of cluster & BIC & BIC changes & Ratio of BIC changes & Ratio of distance measures \\
\hline 1 & 9091.825 & & & 1.632 \\
2 & 8423.050 & -668.774 & 1.000 & 1.653 \\
4 & 8132.304 & -290.746 & 0.435 & 1.031 \\
5 & 8078.010 & -54.294 & 0.081 & 1.215 \\
6 & 8034.455 & -43.556 & 0.065 & 1.462 \\
7 & 8052.998 & 18.544 & -0.028 & 1.047 \\
8 & 8163.000 & 110.002 & -0.164 & 1.019 \\
9 & 8281.894 & 118.894 & -0.178 & 1.031 \\
10 & 8404.353 & 122.459 & -0.183 & 1.239 \\
11 & 8532.439 & 128.086 & -0.192 & 1.113 \\
12 & 8695.171 & 162.732 & -0.243 & 1.185 \\
13 & 8872.636 & 177.464 & -0.265 & 1.060 \\
14 & 9070.488 & 197.852 & -0.296 & 1.017 \\
15 & 9274.575 & 204.087 & -0.305 & 1.021 \\
\hline
\end{tabular}

Since she visits every week, she has needs for more open hours and space. She mostly visits the deck walkway and coniferous garden where she is engaged in dynamic activities such as walking and stretching. Type 2 is 'appreciating nature in the neighborhood' type, with the pattern of two students in their 20s visiting Hongneung Experimental Forest on foot for the first time to appreciate nature. They tend to find the facilities inconvenient such as drinking fountains, trach cans and rest areas and closely examine information boards to obtain information about nature. Type 3 is 'group social gathering' type, with a group of five or more people visiting Hongneung Experimental Forest after being introduced by someone they know. They visit from Seoul (except Dongdaemun-gu) to promote friendship using public transportation. They mostly obtained knowledge and enjoyed experience at Forest Science Exhibition Hall or Hongneung site, showing relatively high satisfaction but facing difficulty in use due to lack of information boards (Table 6).

\section{Developing persona-based scenarios}

A persona must take a general form that can be understood commonsensically and can obtain consent from stakeholders (Song, 2009), and even the most precise and specif- ic details must be described (Lee et al., 2007). Therefore, personas were derived considering detailed elements such as name, age and occupation, and the context scenarios were designed based on the types classified according to the purpose and characteristics of the personas.

The context scenarios for the three types of personas describe the key factors of each space and how the persona models perform each factor of visitor activities. The contents of each scenario are based on the data of quantitative and qualitative analysis results above (personal characteristics, user characteristics, overall behavior, points to improve, satisfaction, experience, relationship with the design subject, knowledge and skills, etc.). Moreover, problems and requirements in the area could be determined through the usage patterns and scenario details.

Persona 1 'Park, Woondong' visits Hongneung Experimental Forest every weekend to exercise in the neighborhood. Thus, she hopes there are more various contents regarding the routes or environment at the forest. For that reason, in addition to appreciating nature, she overcomes the dullness of the environment by conducting dynamic activities such as walking quickly, stretching, walking barefoot and clapping for health rather than doing something static. Since her main purpose of visit is to walk quickly for exercise, she tends to have a longer circulation than other types of personas and 
needs an open space to more broadly see the city landscape (Table 7).

The context scenario of Persona 2 'Lee, Jayeon'(Table 8) shows that users that are local residents but are visiting for the first time tend to actively use the forest by walking slowly and touching trees and plants, taking photos and looking at the names of trees. Those whose purpose is to obtain information about the forest pointed out that the biggest thing to improve is lack of information boards that describe the forest. Their places of visit also require consideration such as universal design as there are many constraints for wheelchairs, such as deck walkways that are not on a dirt road or places concentrated on the sides of the road.

Table 6. Types of personas

\begin{tabular}{|c|c|c|c|c|}
\hline & \multirow{2}{*}{ Characteristics } & \multicolumn{3}{|c|}{ Type $(\%)^{\mathrm{z}}$} \\
\hline & & Type 1 & Type 2 & Type 3 \\
\hline \multirow{5}{*}{$\begin{array}{c}\text { Personal } \\
\text { characteristics }\end{array}$} & $\operatorname{Age}\left(\mathrm{x}^{2}=180.53 * * *\right)$ & Over $60 \mathrm{~s}(31.0)$ & $20 \mathrm{~s}(43.4)$ & $50 \mathrm{~s}(37.6)$ \\
\hline & Residential area $\left(\mathrm{x}^{2}=122.16^{* * *}\right)$ & Dongdaemun-gu(87.6) & Dongdaemun-gu(53.0) & Seoul except Dongdaemun-gu(77.6) \\
\hline & Occupation $\left(\mathrm{x}^{2}=127.24 * * *\right)$ & Housewife(29.5) & Student(28.9) & Employee/public official(31.8) \\
\hline & Hobbies & Outdoor-activity type & Outdoor-activity type & Indoor-activity type \\
\hline & Participating groups & Few or no activities & $\begin{array}{l}\text { Variety of activities } \\
\text { (NGO, religion, etc.) }\end{array}$ & Alpine club \\
\hline \multirow{7}{*}{$\begin{array}{c}\text { Visit } \\
\text { characteristics }\end{array}$} & $\operatorname{Motivation}\left(\mathrm{x}^{2}=67.14 * * *\right)$ & $\operatorname{Nearby}(63.6)$ & $\operatorname{Nearby}(63.6)$ & Recommendation(44.7) \\
\hline & Experience $\left(\mathrm{x}^{2}=103.00 * * *\right)$ & Visited(96.9) & Never visited(53.0) & Never visited (64.7) \\
\hline & Frequency $\left(\mathrm{x}^{2}=108.41^{* * *}\right)$ & Once or twice a month(27.9) & None(48.2) & None(41.2) \\
\hline & Transportation $\left(\mathrm{x}^{2}=125.02 * * *\right)$ & On foot $(82.9)$ & On foot $(53.0)$ & Public transportation $(60.0)$ \\
\hline & $\operatorname{Purpose}\left(\mathrm{x}^{2}=76.59 * * *\right)$ & Health(38.0) & Appreciating nature(21.7) & Social interaction(30.6) \\
\hline & \multirow{2}{*}{ Companions $\begin{array}{cc}\operatorname{type}\left(\mathrm{x}^{2}=101.17^{* * *}\right) \\
\operatorname{number}\left(\mathrm{x}^{2}=69.70^{* * *}\right)\end{array}$} & Family and relatives $(63.6)$ & Friends or couple(31.3) & Organization(43.5) \\
\hline & & $2(46.5)$ & $2(47.0)$ & $>5(36.5)$ \\
\hline Behavior & $\begin{array}{l}\text { Behavior before } \\
\text { and after the visit }\end{array}$ & Home-Hongneung-home & $\begin{array}{l}\text { Home-Hongneung-outside } \\
\text { (restaurant, market, bathhouse, } \\
\text { educational institution) }\end{array}$ & $\begin{array}{l}\text { Home-Hongneung-outside } \\
\text { (restaurant) }\end{array}$ \\
\hline & $\begin{array}{l}\text { Improvements } \\
\text { Overall satisfaction }\end{array}$ & $\begin{array}{l}\text {-Needs extended opening } \\
\text { hours and space }\end{array}$ & $\begin{array}{l}\text {-Needs more drinking } \\
\text { fountains and trash bins } \\
\text {-Needs more rest areas } \\
\text {-Needs wheelchair friendly trails }\end{array}$ & $\begin{array}{l}\text {-High visitor satisfaction } \\
\text {-Needs more name tags of trees } \\
\text { and road signs for amenities }\end{array}$ \\
\hline \multirow{3}{*}{$\begin{array}{l}\text { Empirical } \\
\text { elements }\end{array}$} & \multirow{3}{*}{$\begin{array}{l}\text { Places to visit/ } \\
\text { factors of activities }\end{array}$} & $\begin{array}{l}\text { (Coniferous garden) } \\
\text { Walking barefoot, } \\
\text { Stretching, Clapping for } \\
\text { health }\end{array}$ & $\begin{array}{l}\text { (Coniferous garden) Walking } \\
\text { slowly, Checking the name } \\
\text { tags of trees, Touching the } \\
\text { bark, Taking pictures }\end{array}$ & $\begin{array}{l}\text { (Coniferous garden) } \\
\text { Checking the } \\
\text { name tags of trees }\end{array}$ \\
\hline & & $\begin{array}{l}\text { (Deck walkway) Hearing \& } \\
\text { smelling the forest }\end{array}$ & $\begin{array}{l}\text { (Deck walkway) Walking, } \\
\text { pushing the wheelchair }\end{array}$ & $\begin{array}{l}\text { (Former site of Hongneung) Taking } \\
\text { a rest, reading information board }\end{array}$ \\
\hline & & $\begin{array}{l}\text { (Scenic Tree Species } \\
\text { Garden) Smelling the } \\
\text { flowers, appreciating nature }\end{array}$ & $\begin{array}{l}\text { (Millenium Hill) Taking a rest, } \\
\text { using vending machines }\end{array}$ & $\begin{array}{l}\text { (Forest Science Exhibition Hall) } \\
\text { Seeing exhibits, using amenities }\end{array}$ \\
\hline $\begin{array}{l}\text { Relationship } \\
\text { toward the objects }\end{array}$ & Nature Relatedness Scale(NRS) & $21.40 / 30$ points & $21.44 / 30$ points & $21.43 / 30$ points \\
\hline \multirow{5}{*}{$\begin{array}{l}\text { Skills and } \\
\text { knowledge }\end{array}$} & \multirow{5}{*}{ Knowledge of forest ecosystem } & 9.20 insect species & 9.48 insect species & 9.24 insect species \\
\hline & & 6.97 bird species & 7.28 bird species & 7.01 bird species \\
\hline & & 19.80 flower species & 19.97 flower species & 20.00 flower species \\
\hline & & 16.27 tree species & 16.50 tree species & 16.41 tree species \\
\hline & & Sum 52.23 species & Sum 53.23 species & Sum 52.66 species \\
\hline
\end{tabular}

${ }^{\mathrm{z}}$ Type $1, \mathrm{n}=129$; Type $2, \mathrm{n}=83$; Type $3, \mathrm{n}=85$.

$* * * p<.001$. 
Table 7. Context scenario of Persona 1

\begin{tabular}{|c|c|c|}
\hline \multicolumn{3}{|c|}{ Persona 1: Park, Woondong } \\
\hline Factors of activities & Scenario & $\begin{array}{l}\text { Behavior pattern \& design } \\
\text { requirements through scenario }\end{array}$ \\
\hline- & $\begin{array}{l}\text { (1) Park, Woondong, a } 70 \text {-year-old housewife living in Dongdaemun-gu, visits } \\
\text { Hongneung Forest by walking for } 10 \text { minutes with her partner at } 9 \text { a.m. }\end{array}$ & \multirow{8}{*}{$\begin{array}{l}\text { - Needs for extending opening } \\
\text { hours \& space } \\
\text { - Lack of contents/ interesting } \\
\text { factors } \\
\text { - Needs a viewpoint for city } \\
\text { landscape }\end{array}$} \\
\hline- & $\begin{array}{l}\text { (2) Park plans to walk around without checking the guide map, since Park visits } \\
\text { here regularly every month. }\end{array}$ & \\
\hline $\begin{array}{l}\text { Walking, stretching, } \\
\text { clapping for health }\end{array}$ & $\begin{array}{l}\text { (3) Park walks along the deck walkway, stretching and clapping for her health } \\
\text { starting from the Coniferous garden. Park is familiar with a lot of insects } \\
\text { and plants since she has already been here several times. }\end{array}$ & \\
\hline $\begin{array}{l}\text { Walking barefoot, } \\
\text { listening to the forest, } \\
\text { smelling the forest }\end{array}$ & $\begin{array}{l}\text { (4) Park walks barefoot a little faster for exercise along the inclined trail to } \\
\text { 'Scenic Tree Species Garden'. Park prefers this natural trail because it is } \\
\text { completely wild. Park hears, smells and feels the nature. }\end{array}$ & \\
\hline- & $\begin{array}{l}\text { (5) Park is curious about the blocked trail towards 'Scenic Tree Species } \\
\text { Garden.' Park would like to go in, but it is not open. }\end{array}$ & \\
\hline $\begin{array}{l}\text { Smelling the flowers, } \\
\text { appreciating scenery }\end{array}$ & $\begin{array}{l}\text { (6) Park smells the flowers in 'Scenic Tree Species Garden,' and appreciates } \\
\text { the city landscape from above, but she can't see much of the view. }\end{array}$ & \\
\hline- & (7) Less than 2 hours later, Park is finished and goes home. & \\
\hline- & $\begin{array}{l}\text { (8) As Park visits here every weekend, she feels a little tired of the course and } \\
\text { the environments. }\end{array}$ & \\
\hline
\end{tabular}

Table 8. Context scenario of Persona 2

\begin{tabular}{|c|c|c|}
\hline \multicolumn{3}{|c|}{ Persona 2: Lee, Jayeon } \\
\hline Factors of activities & Scenario & $\begin{array}{l}\text { Behavior pattern \& design } \\
\text { requirements through scenario }\end{array}$ \\
\hline- & $\begin{array}{l}\text { (1) Lee, Jayeon, a 25-year-old student living in Dongdaemun-gu, plans to visit } \\
\text { Hongneung Forest for the first time with a neighborhood friend who is also } \\
\text { Lee's school club member. Lee's friend visits in a wheelchair, since she } \\
\text { recently injured her leg. }\end{array}$ & \multirow{9}{*}{$\begin{array}{c}\text { Coniferous } \\
\text { garden. } \\
\text { Deck road }\end{array}$} \\
\hline Waiting & $\begin{array}{l}\text { (2) After waiting for Lee's friend, Lee meets her at the main gate of Hongneung } \\
\text { Forest at around } 1 \text { p.m. after going for a bath in the morning. }\end{array}$ & \\
\hline- & $\begin{array}{l}\text { (3) As Lee likes hiking and taking walks, Lee used to visit Bukhansan Dulle-gil } \\
\text { trail more often than Hongneung Forest which is located nearby. Today, Lee } \\
\text { visits Hongneung Forest that has many plants and trees for the purpose of } \\
\text { appreciating nature. }\end{array}$ & \\
\hline $\begin{array}{l}\text { Walking slowly, checking } \\
\text { name tags of trees, touching } \\
\text { the bark, taking pictures }\end{array}$ & $\begin{array}{l}\text { (4) As Lee visits here for the first time, Lee goes straight into the Coniferous } \\
\text { garden looking at the guide map carefully at the beginning. Walking slowly, } \\
\text { Lee checks the name tags of trees, touches the bark, and takes some pictures. }\end{array}$ & \\
\hline Pushing wheelchair & $\begin{array}{l}\text { (5) Lee pushes the friend in the wheelchair on the deck walkway rather than the } \\
\text { forest trail which is difficult for the wheelchair. Lee goes to the information } \\
\text { board on the side of the Millennium Hill. }\end{array}$ & \\
\hline Reading information board & $\begin{array}{l}\text { (6) Lee reads the information board carefully which contains the data about } \\
\text { public interests of forests to get information. Lee wishes there was more content. }\end{array}$ & \\
\hline $\begin{array}{l}\text { Taking a rest, using vending } \\
\text { machine }\end{array}$ & $\begin{array}{l}\text { (7) Lee wants to look around more, but it is not easy to push a wheelchair around } \\
\text { because there is gravel on the dirt road. Lee tries to rest on a bench in the } \\
\text { shady place, but many people are sitting. After waiting for a long time, Lee } \\
\text { takes a rest on a bench, pulling out a drink from a vending machine. }\end{array}$ & \\
\hline- & $\begin{array}{l}\text { (8) To fill their bottle before leaving, Lee tries to look for a drinking fountain, } \\
\text { but Lee can't see it. }\end{array}$ & \\
\hline- & (9) After appreciating nature for about 2 hours, Lee exits the Hongneung Forest. & \\
\hline
\end{tabular}


The context scenario of Persona 3 'Kim, Moim' showed the user characteristics, behaviors and needs. Group users who first visited the forest tended to face great inconveniences in information facilities such as informational boards and signposts. There is especially a difficulty in determining the current location and direction from the comprehensive information board at the main gate. Some people also face difficulty finding the way if they climbed up through the forest walkway due to lack of signposts. Many users also had a hard time finding amenities due to lack of information boards about restrooms on the walkway. The lack of signposts resulted in short visit circulation as they cannot look around the entire forest (Table 9).

\section{Conclusion}

To efficiently plan and form a forest recreation area, it is necessary to analyze user characteristics and patterns through questionnaire surveys and interviews, while also subdividing and multidimensionally analyzing the characteristics based on user values and personalities. Therefore, this study applied the PSM with the case of Hongneung Experimental Forest to subdivide and determine user needs and behaviors of forest recreation areas. To achieve the goal above, we came up with factors of visitor activities in Hongneung Experimental Forest based in the results of the field study and set personas based on the surveyed user characteristics, thereby presenting archetypes of scenarios.

First, we came up with key factors through observation

Table 9. Context scenario of Persona 3

\begin{tabular}{|c|c|c|}
\hline \multicolumn{3}{|c|}{ Persona 3: Kim, Moim } \\
\hline Factors of activities & Scenario & $\begin{array}{l}\text { Behavior pattern \& design } \\
\text { requirements through scenario }\end{array}$ \\
\hline- & $\begin{array}{l}\text { (1) Kim, a 55-year-old office worker got to know Hongneung Forest from his } \\
\text { co-worker and decided to visit for the first time this weekend with six Rotary club } \\
\text { members for socializing. }\end{array}$ & \multirow{10}{*}{$\begin{array}{l}\text { The former site } \\
\text { of Hongneung } \\
\text { Coniferous } \\
\text { garden Forest Science } \\
\text { Exhibition Hall }\end{array}$} \\
\hline Waiting & $\begin{array}{l}\text { (2) Kim, who lives in Seongbuk-gu, gets off at Korea University Station by subway } \\
\text { and arrives early in the morning at 9:30 a.m. in time for the opening time and waits } \\
\text { for his party. }\end{array}$ & \\
\hline- & $\begin{array}{l}\text { (3) Since Kim usually enjoys indoor activities such as watching TV and movies rather } \\
\text { than outdoor activities, Kim doesn't have much knowledge about forests such as } \\
\text { insects, birds, wild flowers and trees, which makes him feel unfamiliar. }\end{array}$ & \\
\hline $\begin{array}{l}\text { Checking the } \\
\text { guide map \& name } \\
\text { tags of trees }\end{array}$ & $\begin{array}{l}\text { (4) Kim checked the guide map in front of the main gate, but it is not easy to } \\
\text { understand the site. First, Kim plans to walk around starting from the Coniferous } \\
\text { garden and to check the name tags of trees. }\end{array}$ & \\
\hline Seeing exhibits & $\begin{array}{l}\text { (5) As Kim walked along the deck walkway in the Coniferous garden, Kim came out } \\
\text { to see the exhibits at the Forest Science Exhibition Hall. }\end{array}$ & \\
\hline $\begin{array}{l}\text { Looking } \\
\text { information board, } \\
\text { taking a rest }\end{array}$ & $\begin{array}{l}\text { (6) As Kim walked along the forest trail past the Forest Science Exhibition Hall, Kim } \\
\text { found a place called 'The former site of the emperor Myeongseong tomb' and } \\
\text { took a short rest in the shade, looking at the information board about its history. }\end{array}$ & \\
\hline- & $\begin{array}{l}\text { (7) Kim was going to walk around from 'The former site,' but couldn't find any road } \\
\text { sign about the trail. Kim also tried to go to the toilet after wandering for a long } \\
\text { time, but couldn't find any information about the amenities. }\end{array}$ & \\
\hline Using amenities & $\begin{array}{l}\text { (8) After wandering for a long time, Kim ends up going back down to the Forest } \\
\text { Science Exhibition Hall, stopped by the toilet and went down the deck walkway } \\
\text { into the Coniferous garden again. }\end{array}$ & \\
\hline- & $\begin{array}{l}\text { (9) Kim feels pretty satisfied with Hongneung forest, which Kim visited for the first } \\
\text { time, because Kim doesn't usually visit the natural environment. }\end{array}$ & \\
\hline- & (10) Kim visited for about $2 \sim 3$ hours in the morning and went to a restaurant for lunch. & \\
\hline
\end{tabular}


survey and observer's brainstorming and used questionnaire survey data such as demographic and visit characteristics to conduct statistical analyses such as two-stage cluster analysis and cross-tabulation analysis, thereby coming up with three clusters. Then we conducted a qualitative analysis based on data obtained from observation survey and interview on each cluster's hobbies, participating group activities, activities before and after the visit, points to improve, places of visit, knowledge about forests, values about nature, etc. and developed three types of personas and context scenarios.

The key findings of this study are as follows. First, as a result of conducting observation survey on 14 spots in Hongneung Experimental Forest, we came up with 64 factors of visitor activities by space and selected 25 key factors through observer's brainstorming. Second, we ultimately came up with three types of personas considering key factors and data obtained from quantitatively and qualitatively analyzing user characteristics through the questionnaire survey and interview. Third, key factors of each space were applied according to the characteristics of each persona to come up with context scenarios, through which we could determine the problems in terms of space as well as user needs. In other words, we found that it is possible to closely determine parts that are not revealed in detail such as user values and experiences by overcoming the limitations of questionnaire surveys that have been conducted superficially in terms of age, gender, duration of stay and purpose of use to determine user characteristics. In this aspect, the PSM applied in this study is useful when creating and improving a 'user-centered' environment and coming up with space planning factors.

Comparing the results of context scenarios for each of the three types of personas, we can discover that there are differences in performing a series of forest experience activities among the three personas, which imply that we must approach space planning in different ways depending on the user. Moreover, the PSM was mostly a method used to closely analyze user needs in software and product design and has never been applied to the natural environment such as forest recreation and landscape, but through this study we discovered the possibility that this methodology can be adequately used to determine user characteristics of forest recreation areas.

This study has significance in that it strengthened the user perspective by setting up personas that represent various user bases beyond the limitations of analyzing comprehensive user characteristics and reviewed applicability of the PSM. The developed personas will be useful in coming up with planning factors and setting the direction for planning considering user values, patterns and actions when designing a certain space from the 'user perspective'. Furthermore, it will be possible to more efficiently use the results of scenario design by discussing detailed goals and direction setting in personal development.

\section{References}

Ahn, J.H., H.W. Kwon, W.T. Kim, and S.Y. Kim. 2014. Service design development for the development of regional culture in a smart city: Focused on vitalizing busking culture. Des. Converg. Study 13(3):205-216.

An, S.Y. and S.Y. Kim. 2015. The user scenario development of a residential area style U-city experience zone in Sejong city based on persona model. J. Digit. Des. 15(3):59-70.

Anvari, F., D. Richards, M. Hitchens, M.A. Babar, H.M.T. Tran, and P. Busch. 2017. An empirical investigation of the influence of persona with personality traits on conceptual design. J. Syst. Softw. 134:324-339. https://doi.org/10.1016/j.jss.2017.09.020

Chang, B.M. 2001. Factors affecting user's satisfaction in development of natural recreation forest. J. Korean Inst. Landsc. Archit. 29(3):19-28.

Chang, B.M. and M.K. Bae. 2001. Differences in resources of natural recreation forest developed by public and private body. J. Korean Inst. Landsc. Archit. 29(4):24-33

Cho, W.H. and S.B. Im. 2013. A study on the relationship between visual preferences and visitors' satisfaction in Bukhansan Dulegil. J. Korean Inst. Landsc. Archit. 41(1):1-11.

Choi, G.Y. and T. Kim. 2015. A study on the management plan of Hongneung Forest based on visitor 
monitoring. J. Korean For. Sci. 104(3):443-453. https://doi.org/10.14578/jkfs.2015.104.3.443

Chung, H.K. 2013. Study on personas for SNS mobile application: Focused on Kakaotalk. J. Korea Des. Forum 40:29-38. https://doi.org/10.21326/ksdt.2013..40.003

Cooper, A. 2004. The inmates are running the asylum: Why high tech products drive us crazy and how to restore the sanity (Vol. 2). Indianapolis, IN: Sams Publishing.

Cooper, A., R. Reimann, and D. Cronin. 2007. About face 3: The essentials of interaction design. Indianapolis, IN: Wiley Publishing.

Jang, Y.S. and Y.H. Son. 2017. A study on user behavior of forest therapeutic trails: Focusing on case of Korea and Japan. J. Korean Inst. For. Recreat. 21(3):35-45. https://doi.org/10.34272/forest.2017.21.3.004

Jeong, S.Y. and S.G. Jung. 2014. A study on framework of persona components. J. Digit. Des. 14(4):407-416.

Kang, M.A., J.Y. Son, and H.J. Kim. 2007. An exploratory application of the mixed methods research: Application of surveys and focus group interviews for regional public health issue decision making. Korean Public Adm. Rev. 41(4):415-437.

Kang, S.J. and Y.G. Kwon. 2005. A study on applying concepts of interaction design to space. J. Korean Inst. Int. Des. 14(3):234-242.

Kim, S.Y. and S.Y. An. 2018. A Study on the development of user centered smart city experience scenario-using local spatial information and the persona model. J. Korea Contents Assoc. 18(6):333-341.

Kim, T.H. 2016. A study on the location plans of campsites in recreational forests. Doctoral dissertation, Chonbuk National University, Jeonju, Korea.

Kim, T.W. 2016. Study on user's satisfaction with regard to importance between facility and program of natural forest management: Focusing on "Natural Forest" in Daejeon. Master's thesis, Paichai University, Daejeon, Korea.

Kim, Y.H. 2016. The analysis of program preferences for the development of forest therapy program. Korean J. Environ. Ecol. 30(1):118-129.
Kwon, O.J., Y.M. Lee, D.S. Kim, O.K. Lee, and J.S. Yim. 2017. Developing scenario for elderly residents behaviors at home using persona-based scenario method. J. Korean Hous. Assoc. 28(3):65-74.

Lee, H.J., Y.M. Kim, J.H. Park, D.M. Kim, and H.Y. Ryoo. 2007. Investigating user activities \& generating personas for U-zone development. J. Digit. Des. 7(4):81-90.

Lee, J.H. 2013. Psycho-property Test and Validity for Korean version of Nature Relatedness Scale. Doctoral dissertation, Chungbuk National Univeristy, Cheongju, Korea.

Lee, J.H., K.H. Min, and Y.H. Son. 2015. Universal design principles for forest welfare service using semantic network analysis. J. Korean Soc. Rural Plan. 21(2):51-61.

Lee, J.M. 2013. A study on the types of Human-centered Design and the analysis of the correlation between each type and need hierarchy. J. Basic Des. Art 14(3):233-243.

Lee, J.W. and K.S. Nam. 2015. Extraction of an improvement plan of day care center's interior environment design reflecting persona characteristics: The case of Jounno Ward Silver Center. J. Korean Inst. Int. Des. 24(1):43-53. https://doi.org/10.14774/JKIID.2015.24.1.043

Miaskiewicz, T. and K.A. Kozar. 2011. Personas and user-centered design: How can personas benefit product design processes? Des. Stud. 32(5):417-430. https://doi.org/10.1016/j.destud.2011.03.003

Oh, S.H., J.H. Kim, and H.H. Choi. 2010. A study on personas models for car navigation developing. J. Korea Soc. Comput. Inf. 15(8):163-171.

Olsen, G. 2004. Persona creation and usage toolkit. Retrieved from http://www.interactionbydesign.com/presentations/olsen_persona_toolkit.pdf

Ryu, Y.S. 2017. Case study of the satisfaction analysis to establish and improve forest experiences for children: The forest experience for children at Apsan Park in Daegu. J. Environ. Sci. Int. 26(11):1223-1233. https://doi.org/10.5322/JESI.2017.26.11.1223

Son, J.W. and S.Y. Ha. 2012. A study on visitor's behavior as a characteristics of different forest trails. J. 
Korean For. Soc. 101(2):309-316.

Song, J.H. 2006. Ubiquitous house model based on the human behavior. Doctoral dissertation, Yonsei Univeristy, Seoul, Korea.

Song, K. 2009. Wayfinding planning in public space using persona-based scenario method. J. Urban Des. Inst.
Korea 10(1):21-34.

Wiegers, K.E. 2003. Software requirements 2 (2nd ed.). Redmond, MA: Microsoft Press.

Zaller, J.R. 1992. The nature and origins of mass opinion. New York, NY: Cambridge University Press. 